\title{
PERAN PERKEMBANGAN MORAL TERHADAP PERILAKU PROSOSIAL REMAJA
}

\author{
Fredericksen Victoranto Amseke ${ }^{1}$, Marleny Purnamasary Panis ${ }^{2}$ \\ Program Studi Pendidikan Kristen Anak Usia Dini, Institut Agama Kristen Negeri Kupang ${ }^{1}$ \\ Program Studi Psikologi, Universitas Nusa Cendana ${ }^{2}$ \\ fredericksenamseke@yahoo.co.id
}

\begin{abstract}
The purpose of this study was to determine the effect of moral development on prosocial behavior in students grade VIII in SMP Negeri" $X^{\prime \prime}$ at Kota Kupang. This is a quantitative research. The research's population was all students grade VIII in SMP Negeri " $X$ " at Kota Kupang with the total amount of 352 students. A sample of 78 students was taken by cluster random sampling technique. Instruments data collection were the scale of moral development and the scale of prosocial behavior. The data analysis technique was simple linear regression. Correlation analysis results show significant positive correlation between moral development and prosocial behavior with $R=0.568$. Simple linear regression analysis was performed to predict prosocial behavior based on moral development $(F=36,188, p=0.000(<0.05)$ with coefficient determination $R 2=0.323$, which means that the influence of moral development on prosocial behavior in students grade VIII in SMP Negeri "X" at Kota Kupang is 32.3\%. This study shows the level of moral development in students grade VIII in SMP Negeri "X" at Kota Kupang is categorized as high at the level of $43.7 \%$ while at the same time the level of prosocial behavior is also in the high category at the level of 39.7\%. The increased level of moral development relates to the higher level of prosocial behavior in adolescents.
\end{abstract}

Keywords: Moral Development, Prosocial Behavior

\begin{abstract}
ABSTRAK
Tujuan penelitian ini untuk mengetahui pengaruh perkembangan moral terhadap perilaku prososial pada siswa kelas VIII di SMP Negeri "X" Kota Kupang. Penelitian ini adalah penelitian kuantitatif. Populasi penelitian adalah seluruh siswa kelas VIII di SMP Negeri "X" Kota Kupang berjumlah 352 siswa. Sampel berjumlah 78 siswa diambil dengan teknik cluster random sampling. Instrumen pengumpulan data adalah skala perkembangan moral dan skala perilaku prososial. Teknik analisis data adalah regresi linear sederhana. Hasil analisis korelasi menunjukkan korelasi positif yang signifikan antara perkembangan moral dan perilaku prososial dengan nilai $\mathrm{R}=0,568$. Analisis regresi linear sederhana dilakukan untuk memprediksi perilaku prososial berdasarkan perkembangan moral $(\mathrm{F}=36,188, \mathrm{p}=0,000(<$ $0,05)$ dengan nilai koefisien determinasi $\mathrm{R} 2=0,323$. Artinya pengaruh perkembangan moral terhadap perilaku prososial siswa kelas VIII di SMP Negeri "X" Kota Kupang sebesar 32,3\%. Penelitian ini menunjukkan tingkat perkembangan moral siswa kelas VIII di SMP Negeri "X" di Kota Kupang dikategorikan tinggi pada level 43,7\%, sementara itu pada saat yang sama tingkat perilaku prososial juga berada pada kategori tinggi pada level 39,7\%. Semakin tinggi perkembangan moral semakin meningkat pula perilaku prososial remaja.
\end{abstract}

Kata Kunci: Perkembangan Moral, Perilaku Prososial. 


\section{PENDAHULUAN}

Periode remaja merupakan masa perkembangan transisi dari masa kanak-kanak menuju masa dewasa yang melibatkan perubahan pada aspek biologis, kognitif, dan sosioemosional yang dimulai pada sekitar usia 10 hingga 13 tahun dan berakhir pada usia dua puluhan atau pada awal periode dewasa muda (Santrock, 2016). Masa remaja ditandai oleh proses pencarian identitas diri, membangun relasi, dan berkembangnya minat untuk mencari tahu tentang karir (Santrock, 2016). Proses interaksi sosial semakin banyak dipelajari pada masa ini sehingga muncul perilaku prososial yang menjadi standar etika bagi masyarakat Indonesia yang mengutamakan nilai gotong royong (Bashori, 2017).

Perilaku prososial adalah tindakan, sikap, dan nilai-nilai yang mendorong seseorang dengan maksud memberi manfaat secara langsung bagi orang lain (Ewest, 2018). Menurut Baron dan Branscombe (2016), perilaku prososial bersifat sukarela dan tanpa paksaan. Shadiqi (2018) mendefinisikan perilaku prososial sebagai setiap bentuk tindakan sukarela untuk menolong orang lain sehingga memberi manfaat positif bagi si penerima bantuan dan mungkin tidak memberi manfaat langsung pada si pemberi pertolongan. Selain itu, perilaku prososial terlihat dalam perilaku menjalin relasi dan kerja sama dengan orang lain yang membawa manfaat dan keuntungan bagi setiap pihak yang terlibat (Atkins, Wilson, \& Hayes, 2019). Menurut Mussen dan Eisenberg (1989), perilaku prososial terlihat dalam perilaku berbagi, kerja sama, menolong, jujur, dan berderma. Dengan demikian, tampak bahwa perilaku prososial memiliki unsur nilai moral yang mendorong seseorang menunjukkan perilaku berdasarkan norma sosial yang membawa dampak kebaikan baik bagi hidup orang lain maupun kehidupan bersama dalam lingkungan sosial. 
Perilaku prososial sendiri tergolong perilaku yang dipelajari (Matondang, 2016; Knight, Mazza, Carlo, 2017). Remaja mempelajari norma dan perilaku yang ditunjukkan oleh orang dewasa. Akan tetapi, kecenderungan individual untuk menunjukkan empati merupakan faktor utama yang menyebabkan munculnya perilaku prososial (Knafo-Noam, Uzefovsky, Israel, Davidov, \& Zahn-Waxler, 2015); berbeda dengan kecenderungan kepribadian kikir yang menyebabkan individu sulit berbagi karena adanya persepsi kelangkaan akan apa yang dimiliki (Bashori, 2017). Menurut Eisenberg dkk (dalam Shadiqi, 2018), perilaku prososial berkembang karena adanya kecenderungan empati/simpati yang didukung dengan perasaan terhubung secara sosial yang dipelajari melalui pembentukan kelekatan, kehangatan dalam keluarga, disiplin dan prinsip hidup yang positif, serta partisipasi sosial. Selain empati, nilainilai moral yang dianut individu juga berpengaruh pada sejauh mana ia terlibat dalam tindakan prososial (Kaur, Singh, \& Kaur, 2019).

Perkembangan emosi moral dan empati menggambarkan masa remaja sebagai masa dimana remaja mulai peka dan mudah memahami perilaku prososial seperti berbagi dan sukarela (Bandy \& Wilhelm, 2012; Van der Graaff, Carlo, Crocetti, Koot, \& Branje, 2018). Namun, penelitian lain menemukan bahwa remaja mengalami penurunan kepedulian sosial dan kepekaan terhadap orang lain dan lingkungan terkait proses dan waktu sejak terjadi perkembangan saraf di area korteks yang berhubungan dengan kognisi sosial dan kontrol perilaku (Perwitasari, 2010; Ferschmann, Vijayakumar, Grydeland, Overbye, Sederevicius, Due-Tønnessen, Fjell, Walhovd, Pfeifer, \& Tamnes, 2019). Ferschmann dkk (2019) bahkan menemukan bahwa sempat terjadi penurunan fungsi adaptif perilaku prososial ketika remaja akhir berada pada masa transisi menuju masa dewasa muda. 
Menurut Valkenburg dan Piotrowski (2017), di era digital sekarang ini manfaat penggunaan media sosial bagi perkembangan moral remaja seringkali kurang mendapat perhatian . Lebih banyak terjadi kecemasan akan dampak negatif teknologi baru pada remaja seperti keterlibatan pada perilaku-perilaku amoral yang tidak sesuai dengan norma kesopanan dan berkurangnya minat untuk bersosialisasi dengan lingkungan (Valkenburg \& Piowtrowski, 2017). Hasanah dan Kumalasari (2015) berpendapat mengenai penggunaan handphone yang menyebabkan berkurangnya perilaku sosial untuk berkomunikasi tatap muka dengan teman di dunia nyata sehingga remaja cenderung lebih mementingkan diri sendiri. Akibatnya adalah terjadi penurunan nilai-nilai kesetiakawanan, pengabdian, dan tolong menolong dan berkembangnya sikap egois dan rasa individualis. Hal berbeda dikemukakan oleh Pratiwi (2018) yang menemukan bahwa tidak ada hubungan antara intensitas penggunaan smartphone dengan perilaku prososial pada remaja. Dengan demikian, disimpulkan bahwa perilaku prososial pada dasarnya mencerminkan kecenderungan individu dalam berespon terhadap lingkungannya.

Penelitian ini hendak mencari tahu pengaruh perkembangan moral terhadap perilaku prososial. Hal ini perlu dilakukan mengingat perkembangan dan penalaran moral membantu remaja untuk beradaptasi dalam proses pencarian jati diri dan menjadi dasar yang penting untuk memahami perilaku kerja sama prososial dengan lingkungannya (Santrock, 2016). Kemampuan bekerja sama dan berkolaborasi bermanfaat positif dan mampu meningkatkan prestasi akademik anak dan remaja (Gerbino, Zuffianò, Eisenberg, Castellani, Kanacri, Pastorelli, Caprara, 2017; Shirin, 2020). Pendidikan moral dalam keluarga yang mengajarkan nilai-nilai prososial menjadi faktor protektif bagi remaja agar terhindar dari perilaku berisiko mengkonsumsi alkohol, rokok, dan obat-obatan terlarang lainnya (Mak, Leung, \& Loke, 2019). Perilaku prososial juga meningkatkan kemampuan berempati sehingga 
berperan dalam penurunan tingkat agresifitas (Spataro, Calabrò \& Longobardi, 2020). Selain itu, perilaku prososial berhubungan dengan perasaan bahagia dan kemampuan individu untuk mengutamakan perilaku bersyukur serta memaafkan sehingga mampu bertindak berani dan bijaksana dalam menghadapi ketidakadilan yang dialami oleh orang lain dalam situasi sosial (García-Vázquez, Valdés-Cuervo, Martínez-Ferrer, \& Lizeth Parra-Pérez, 2020).

Lado, Ruliati, Damayanti, \& Anakaka (2019) melakukan penelitian pada 360 orang remaja akhir di Kota Kupang dan menemukan bahwa tidak terdapat hubungan antara perkembangan moral dan perilaku prososial. Berdasarkan wawancara dengan guru di SMP Negeri "X" Kota Kupang, diperoleh laporan tentang rendahnya perilaku prososial siswa kelas VIII yang terlihat pada perilaku-perilaku seperti: kurangnya rasa ingin berbagi ilmu dengan meminjamkan catatan mata pelajaran, kurangnya perhatian terhadap hak dan kesejahteraan orang lain, kurangnya empati terhadap permasalahan yang sedang dihadapi oleh teman, kurangnya perilaku bermurah hati untuk memberikan sumbangan sukarela, serta kecenderungan untuk tidak peduli dan membiarkan ketika terjadi konflik terbuka antar individu di lingkungan sekitar (Guru Bimbingan dan Konseling SMP Negeri "X” Kupang, komunikasi personal, 22 Februari, 2019). Blankenstein, Telzer, Do, van Duijvenvoorde, \& Crone (2019) menemukan bahwa pada usia remaja perilaku prososial memiliki konotasi sebagai perilaku berisiko dan keterlibatan pada perilaku prososial menjadi kesempatan bagi remaja untuk mengalami suatu situasi yang menyenangkan. Peneliti berpendapat bahwa perlu dilakukan pengkajian ulang mengenai pengaruh tingkat perkembangan moral terhadap perilaku prososial remaja di Kota Kupang. Tujuan Penelitian ini untuk mengetahui pengaruh perkembangan moral berpengaruh terhadap perilaku prososial siswa kelas VIII di SMP Negeri "X" Kota Kupang. 


\section{METODE PENELITIAN}

Metode dalam penelitian yang digunakan adalah kuantitatif. Subyek penelitian siswa kelas ini adalah siswa kelas VIII SMP Negeri "X" Kota Kupang. Sampel penelitian 78 siswa yang diperoleh melalui teknik cluster random sampling. Alat pengumpul data yang digunakan adalah skala perilaku prososial dengan diperoleh 49 aitem valid, dengan tingkat reliabilitas $=$ 0,827. Skala perkembangan moral diperoleh 47 aitem valid dengan tingkat reliabilitas $=0,829$ yang telah diuji cobakan pada 30 siswa dengan karakteristik yang sama dengan populasi. Pengolahan data menggunakan analisis regresi linear sederhana dengan SPSS 22.0

\section{HASIL PENELITIAN}

Deskripsi statistik data perkembangan moral dan perilaku prososial siswa kelas VIII di SMP Negeri "X" Kota Kupang adalah sebagai berikut:

Tabel 1. Kategori Perkembangan Moral

\begin{tabular}{cccc}
\hline Kategori & Rentang Nilai & $\mathrm{N}$ & $\%$ \\
\hline Sangat Rendah & $187-199$ & 3 & $3,8 \%$ \\
Rendah & $200-212$ & 20 & $25,6 \%$ \\
Tinggi & $213-225$ & 34 & $43,7 \%$ \\
Sangat Tinggi & $226-238$ & 21 & $26,9 \%$ \\
\hline
\end{tabular}

Tabel 1 kategorisasi menunjukkan sejauh mana penyebaran skor perkembangan moral subyek penelitian yaitu siswa kelas VIII di SMP Negeri "X" Kota Kupang . Diperoleh skor sangat tinggi sebesar 26,9\% (21 orang siswa), kategori tinggi sebesar 43\% (34 orang siswa), kategori rendah sebesar $25,6 \%$ (20 orang siswa) dan kategori sangat rendah sebesar 3,8\% (3 orang siswa). Hasil ini sesuai dengan karakteristik masa remaja sebagai masa sensitif perkembangan emosi moral dan empati yang menyebabkan peningkatan perilaku prososial seperti berbagi dan sukarela (Bandy \& Wilhelm, 2012; Van der Graaff, Carlo, Crocetti, Koot, \& Branje, 2018). 
Tabel 2. Kategori Perilaku Prososial

\begin{tabular}{cccc}
\hline Kategori & Rentang Nilai & $\mathrm{N}$ & $\%$ \\
\hline Sangat Rendah & $163-176$ & 6 & $7,7 \%$ \\
Rendah & $177-190$ & 29 & $37,2 \%$ \\
Tinggi & $191-204$ & 31 & $39,7 \%$ \\
Sangat Tinggi & $205-218$ & 12 & $15,4 \%$ \\
\hline
\end{tabular}

Tabel 2 kategorisasi menunjukkan sejauh mana penyebaran skor perilaku prososial siswa kelas VIII di SMP Negeri "X” Kota Kupang. Diperoleh skor sangat tinggi sebesar 15,4\% (12 orang siswa), kategori rendah sebesar 37,2\%(29 orang siswa), kategori sangat rendah sebesar 7,7\% (6 orang siswa), dan skor kategori tinggi sebesar 39,7\% (31 orang siswa). Perbedaan skor perilaku prososial pada siswa kelas VIII di SMP Negeri "X" Kota Kupang menunjukkan bahwa pada masa remaja, perilaku prososial berkembang sebagai kecenderungan respon individual terhadap lingkungan sosialnya. Salah satu proses pencarian jati diri remaja adalah memahami perilaku kerja sama prososial dengan lingkungan (Santrock, 2016). Mungkin saja pada remaja terjadi situasi dimana kepedulian sosial dan kepekaan terhadap orang lain dan lingkungan berkurang terkait proses dan waktu sejak terjadi proses neurobiologis yang berhubungan dengan perkembangan kognisi sosial dan kontrol perilaku (Perwitasari, 2010; Ferschmann, Vijayakumar, Grydeland, Overbye, Sederevicius, DueTønnessen, Fjell, Walhovd, Pfeifer, \& Tamnes, 2019).

Tabel 3. Hasil analisis regresi linear sederhana (F)

\begin{tabular}{lcccc}
\hline \multicolumn{1}{c}{ Hubungan } & F & P & Keterangan & Kesimpulan \\
\hline $\begin{array}{l}\text { Perkembangan Moral dengan } \\
\text { Perilaku Prososial }\end{array}$ & 36,188 & 0,000 & $0,000<$ & $\begin{array}{c}\text { Hipotesis } \\
\text { diterima }\end{array}$ \\
\hline
\end{tabular}

Tabel 4. Hasil nilai koefesien determinasi (R Square)

\begin{tabular}{ccccc}
\hline Model & $\mathrm{R}$ & R Square & Adjusted R Square & $\begin{array}{c}\text { Std. Error of the } \\
\text { Estimate }\end{array}$ \\
\hline 1 & $.568^{\mathrm{a}}$ & .323 & .314 & 9.36259 \\
\hline
\end{tabular}


Tabel 3 dan 4 merupakan ringkasan hasil uji hipotesis secara simultan (F) yang menunjukkan bahwa ada hubungan positif yang signifikan antara perkembangan moral dengan perilaku prososial siswa kelas VIII di SMP Negeri "X" Kota Kupang dengan nilai $p=0,000$ dan $\mathrm{F}=36,188$ dengan $\mathrm{R}$ Square $=0,323$. Sumbangan efektif variabel perkembangan moral dengan perilaku prososial siswa sebesar $32,3 \%$, sementara sisanya $67,7 \%$ dipengaruhi variabel lain yang tidak diteliti dalam penelitian ini.

Tabel 5 Hasil Analisis Regresi Linear Sederjana Uji Parsial (Uji t)

\begin{tabular}{cccccc}
\hline \multicolumn{1}{c}{ Hubungan } & $\beta$ & $\mathrm{T}$ & $\mathrm{P}$ & Keterangan & Kesimpulan \\
\hline $\begin{array}{l}\text { Perkembangan Moral } \\
\text { dengan Perilaku Prososial }\end{array}$ & 0,742 & 6,016 & 0,000 & $0,000<0,05$ & $\begin{array}{c}\text { Hipotesis } \\
\text { diterima }\end{array}$ \\
\hline
\end{tabular}

Tabel 5 merupakan ringkasan hasil uji hipotesis secara parsial (t) yang menunjukkan bahwa perkembangan moral secara signifikan memprediksi skor perilaku prososial, $\beta=0.742$, $\mathrm{t}(76)=6,016, \mathrm{p}<.005$. Hasil ini berarti perkembangan moral pada remaja berhubungan dengan tindakan berbagi, kerja sama, menolong, jujur, dan berderma (Mussen \& Eisenberg, 1989) yang juga sesuai dengan yang dikemukakan oleh Kaur, Singh, \& Kaur (2019) bahwa nilai-nilai moral yang dianut individu juga berpengaruh pada sejauh mana ia terlibat dalam tindakan prososial.

\section{DISKUSI}

Secara umum hasil pengukuran di atas membuktikan bahwa ada pengaruh positif dan signifikan perkembangan moral terhadap perilaku prososial siswa kelas VIII di SMP Negeri "X" Kupang dengan $\mathrm{F}_{\text {hit }}$ sebesar 36,188 pada taraf signifikansi 0,000 $(\mathrm{p}<0,05)$. Perkembangan moral berperpengaruh terhadap perilaku prososial siswa dengan nilai $\mathrm{R}$ square sebesar 0,323 
atau $32,3 \%$ dan sisanya $67,7 \%$ diterangkan oleh variabel yang lain. Dalam penelitian ini dapat dipahami perbedaan dugaan wawancara dalam latar belakang masalah sebelumnya kepada siswa dengan hasil penelitian ini yang diartikan bahwa ternyata prososial remaja yang diajarkan oleh orang tua, teman dan guru di sekolah melalui nilai dan norma-norma sosial telah diinternalisasikan remaja dalam masa transisi sehingga mengalami perubahan fisik dan psikologis melalui perkembangan kognitif dan sosial untuk memiliki sikap dan perilaku positif dengan orang lain dalam berinteraksi sehingga dapat memberikan kontribusi signifikan dalam tahap perkembangan moral remaja.

Menurut Latifah (dalam Sarwono, 2016) remaja adalah suatu masa transisi yang ditandai dengan perkembangan psikologis dan sosial maka sehubungan dengan hal itu secara umum siswa sudah mengetahui perilaku-perilaku yang baik dan positif dan bisa membedakan tindakan yang baik dan buruk. Hal ini juga sejalan dengan Wentzel, (Santrock, 2016) yang menuliskan bahwa perilaku prososial sangat dibutuhkan oleh remaja untuk membangun hubungan yang baik dengan lingkungan. Sementara itu, Setioasih (2016) mengemukakan ada banyak faktor yang mendorong seseorang untuk berperilaku prososial salah satunya adalah personal value and norms yaitu internalisasi nilai-nilai serta norma dalam diri individu. Ketika seseorang melakukan interaksi sosial maka mereka akan mempelajari nilai-nilai dan norma sosial yang berlaku sebagai tolak ukur antara baik dan buruk. Kemampuan penalaran individu terhadap nilai dan norma sosial tersebut dalam ilmu psikologi digambarkan sebagai perkembangan moral.

Santrock (2016) menilai perkembangan moral sebagai perkembangan yang berkaitan dengan aturan dan konvensi mengenai apa yang harus dilakukan oleh manusia dalam interaksinya dengan orang lain. Menurut Kohlberg (Hurlock, 1999) perkembangan moral menjelaskan bagaimana seseorang mengerti akan tanggung jawabnya terhadap lingkungan 
sosialnya dimana seseorang dituntut untuk jujur, saling berbagi, saling menolong, yang sejalan dengan konsep prososial. Konsep perkembangan moral mengedepankan kemampuan kognitif untuk menilai suatu perilaku sesuai dengan konsep moral yang berkembang dalam masyarakat. Konsep moral yang dikembangkan oleh Kohlberg lebih menekankan pada alasan yang menjadi dasar seseorang bisa melakukan suatu tindakan (Hurlock, 1999). Jadi, sebelum individu memutuskan untuk berbuat sesuatu individu akan memikirkan apakah perilaku tersebut baik dan dapat diterima oleh orang lain atau masyarakat.

Pada masa anak-anak individu melakukan penilaian benar atau salah hanya berdasarkan tindakan yang akan mempengaruhi mereka. Artinya seorang anak akan berperilaku baik karena mereka takut akan hukuman yang akan diberikan kepada mereka ketika mereka berbuat buruk. Namun seiring waktu individu akan memahami bahwa mereka mungkin perlu mempertimbangkan kebutuhan - kebutuhan orang lain ketika menentukan mana yang benar dan mana yang salah dalam berperilaku. Dan pada akhirnya mereka akan memahami bahwa benar dan salah perilaku berhubungan dengan sekumpulan standar dan prinsip yang menjelaskan hak-hak manusia, bukan hanya kebutuhan individual. Tidak hanya itu, perkembangan moral juga sangat berkaitan dengan pengembangan hati nurani, kemampuan untuk mengadakan empati dan kemampuan diri bersalah (faktor-faktor afektif) ikut berperan dalam perkembangan moral (Setioasih, 2016).

Bila dilihat dari penjelasan diatas maka sangat mungkin bila perkembangan moral memiliki hubungan dengan munculnya perilaku prososial. Semakin tinggi perkembangan moral individu berarti semakin individu tersebut mengerti mana yang baik untuk dilakukan dan mana yang tidak baik atau dalam arti lain individu dapat menginternalisasi nilai dan norma sosial dengan baik dan semakin tinggi perkembangan moral individu maka semakin luas tolak ukur dalam pengambilan keputusan baik dan buruk. 
Penelitian ini sejalan dengan penelitian Setioasih (2016) yang menyimpulkan bahwa perilaku prososial remaja memiliki hubungan yang positif signifikan dengan perkembangan remaja terlihat dari kontribusi efektif sebesar $62 \%$, dan koefisien korelasi 0,822 . Lebih lanjut, penelitian Dewi (2014) menjelaskan bahwa kegiatan pramuka yang merupakan kegiatan diluar kelas dalam rangka memperluas pengetahuan, meningkatkan keterampilan, dan menginternalisasi nilai-nilai dan aturan-aturan sosial baik nasional maupun global dapat meningkatkan perilaku prososial remaja di SMP Santa Ursula Jakarta. Seperti yang diketahui kegiatan pramuka adalah salah satu wadah pembelajaran moral pada siswa.

\section{KESIMPULAN DAN SARAN}

Berdasarkan hasil penelitian diperoleh kesimpulan bahwa perkembangan moral mempengaruhi perilaku prososial pada remaja. Nilai-nilai moral yang dipelajari remaja terlihat dalam perilaku prososial seperti perilaku berbagi, kerja sama, menolong, jujur, dan berderma. Penelitian ini juga menunjukkan bahwa masa perkembangan perilaku prososial pada remaja merupakan kesempatan membangun relasi yang positif dengan lingkungan. Perkembangan ini menguatkan remaja untuk menunjukkan perilaku prososial pada masa-masa selanjutnya ketika beradaptasi dengan lingkungan sosial

Saran bagi siswa sebagai remaja agar menambah wawasan dengan berdiskusi tentang masalah sosial sehingga dapat membangun interaksi sosial yang sesuai dengan aturan atau ajaran yang berlaku di masyarakat, selain itu agar dapat memecahkan masalah yang dihadapi remaja sehingga ada perubahan untuk diterapkan dalam bersikap dan berperilaku yang baik. Remaja diharapkan dapat membangun kesadaran untuk memperluas pergaulan dan menambah pengalaman bersosial. Bagi akademisi diharapkan dapat memberi manfaat teoritis tentang studi perkembangan moral dan perilaku prososial. Untuk peneliti selanjutnya diharapkan mampu 
untuk menyempurnakan dengan menggunakan konstruk psikologis lain yang diduga berhubungan dengan perilaku sosial seperti altruism, kecerdasan spiritual, regulasi emosi, agresifitas, emosi-emosi sosial, atau kemampuan berkomunikasi.

\section{DAFTAR PUSTAKA}

Atkins, P.W.B., Wilson, D.S., \& Hayes, S.C. (2019). Prosocial: Using evolutionary science to build productive, equitable, and collaborative groups. Oakland: New Harbinger Publications, Inc.

Bandy, R., \& Wilhelm, M.O. (2012). Family structure and income during the stages of childhood and subsequent prosocial behavior in young adulthood. Journal of Adolescence, 35, 1023-1034.

Bashori, K. (2017). Menyemai Perilaku Prososial. Sukma: Jurnal Pendidikan. 1(1), 57-92.

Blankenstein, N. E, Telzer, E.H, Do, K.T, van Duijvenvoorde, A.C.K., \& Crone, E. A. (2019). Behavioral and Neural Pathways Supporting the Development of Prosocial and RiskTaking Behavior Across Adolescence. Child Development. doi:10.1111/cdev.13292

Branscombe, N., \& Baron, R. (2016). Social Psychology. (14th eds.). USA: Pearson Education.

Dewi, K.N. (2014). Pengaruh ekstrakulikuler kepramukaan terhadap perilaku prososial remaja di Smp Santa Ursula Jakarta. Persona, Jurnal Psikologi Indonesia. 03(3), 253-268

Eisenberg, N., \& Mussen, P. H. (1989). The roots of prosocial behavior in children. New York: Wiley.

Ewest, T. (2018). In Prosocial Leadership: Understanding the Development of Prosocial Behavior within Leaders and their Organizational Settings. Palgrave Macmillan, New York.

Farid \& Prawitasari, Y.E. (2011). Hubungan penalaran moral, kecerdasan emosi, religiusitas, dan pola asuh orang tua otoritatif dengan perilaku prososial remaja. Repository Universitas Gajah Mada.

Ferschmann, L., Vijayakumar, N., Grydeland, H., Overbye, K., Sederevicius, D., DueTønnessen, P., Fjell, A.M., Walhovd, K.B., Pfeifer, J.H., \& Tamnes, C.K. (2019). Prosocial behavior relates to the rate and timing of cortical thinning from adolescence to young adulthood. Development Cognitive Neuroscience. https://doi.org/10.1016/j.den.2019.100734.

García-Vázquez, F.I., Valdés-Cuervo, A. A., Martínez-Ferrer, B., \& Parra-Pérez, L. G. (2020). Forgiveness, Gratitude, Happiness, and Prosocial Bystander Behavior in Bullying. 5. Frontiers in Psychology. doi.org/10.3389/fpsyg.2019.02827

Gerbino, M., Zuffianò, A., Eisenberg, N., Castellani, V., Luengo Kanacri, B. P., Pastorelli, C., \& Caprara, G. V. (2017). Adolescents' Prosocial Behavior Predicts Good Grades Beyond Intelligence and Personality Traits. Journal of Personality. https://doi.org/10.1111/jopy.12309.

Hasanah, N., \& Kumalasari, D. (2015). Penggunaan Handphone Dan Hubungan Teman Pada Perilaku Sosial Siswa Smp Muhammadiyah Luwuk Sulawesi Tengah. Harmoni Sosial: Jurnal Pendidikan IPS, 2(1), 55-70. https://doi.org/10.21831/HSJPI.V2I1.4613.

Hurlock, E.B. (1999). Psikologi perkembangan, suatu pendekatan sepanjang rentang kehidupan. Edisi 5. Jakarta: Erlangga 
Kaur, H, Singh, A, Kaur, S. (2019). Empathy and Moral Identity as Predictors of Peer Support Volunteerism for Preventing Farmer Suicide in Punjab. The International Journal of Indian Psychology. 7(2), 376-404

Knafo-Noam, A., Uzefovsky, F., Israel, S., Davidov, M., \& Zahn-Waxler, C. (2015). The prosocial personality and its facets: genetic and environmental architecture of motherreported behavior of 7-year-old twins. Original Research Article. doi:10.3389/fpsyg.2015.00112.

Knight, G.P., Mazza, G.L., Carlo, G. (2017). Trajectories of Familism Values and the Prosocial Tendencies of Mexican American Adolescents. Developmental Psychology, 54(2), 378-384. https://doi.org/10.1037/dev0000436

Lado, I. S., Ruliati, L. P., Damayanti, Y., \& Anakaka, D. L. (2019). Analisis Perkembangan Moral Terhadap Perilaku Prososial Remaja Akhir. Journal of Health and Behavioral Science, 1(2), 112-123. https://ejurnal.undana.ac.id/CJPS/article/view/2091

Mak, Y.M., Leung, D.,\& Loke, A.Y. (2019). The vulnerability to alcohol, tobacco, and drug use of adolescent in Hong Kong: a phenomenological study. Research Article: BMC Pediatrics. https://doi.org/10.1186/s12887-019-1678-1.

Matondang, E.S. (2016). Perilaku Prososial (Prosocial Behavior) Anak Usia Dini dan Pengelolaan Kelas Melalui Pengelompokan Usia Rangkap (Multiage Grouping). Eduhamniora: Jurnal Pendidikan Dasar. 8(1), 34-47.

Perwitasari. (2008). Hubungan antara Religiusitas dengan Perilaku Prososial pada Mahasiswa. Jurnal Psikologi, 12 (5), 87-109.

Pratiwi, A.M.S. (2018). Hubungan Intensitas Penggunaan Smartphone dengan Perilaku Prososial Remaja. Skripsi. Program Studi Psikologi: Universitas Muhammadiyah Surakarta.

Santrock, J. W. (2016). Adolescence. (16th eds.). USA: McGraw-Hill Education.

Setioasih, N.E. (2016). Hubungan antara perkembangan moral dengan perilaku prososial pada remaja. Skripsi. Program Studi Psikologi: Universitas Muhammadiyah Malang

Shadiqi. (2018). Perilaku Prososial. Dalam A. Pitaloka, Z. Abidin, \& M. N. Milla (Eds.). Buku psikologi sosial, pengantar teori dan penelitian. Jakarta: Salemba Humanika.

Shirin, A. (2020). Determining the relationship between academic achievement and prosocial behavior of secondary school students in Dhaka City. International Journal of Research and Reviews in Education. 6-15. doi.org/10.33500/ijrre.2020.06.002

Spataro, P., Calabrò, M., \& Longobardi, E. (2020). Prosocial behaviour mediates the relation between empathy and aggression in primary school children. European Journal of Developmental Psychology. https://doi.org/10.1080/17405629.2020.1731467

Valkenburg, P. M., \& Piotrowski, J.T. (2017). Plugged In: How Media Attract and Affect Youth. New Haven: Yale University Press

Van der Graaff, J., Carlo,G., Crocetti, E., Koot, H, M. \& Branje,S. (2018). Prosocial Behavior in Adolescence: Gender Differences in Development and Links with Empathy. Empirical Reseacrh. 47, 1086-1099. DOI 10.1007/s1064-017-0786-1. 
PSYCHE: JURNAL PSIKOLOGI UNIVERSITAS MUHAMMADIYAH LAMPUNG

ISSN (electronic) 2655-6936 ISSN (printed) 2686-0430 